\title{
LA REGULACION DE LA FALSIFICACION DE LOS DOCUMENTOS EN EL DERECHO ROMANO Y EN LA LEY DE LOS VISIGODOS
}

\author{
Olga Marlasca Martínez
}

\section{Introducción}

Al parecer, la más antigua regulación de la falsedad de documentos tiene relación con la llamada Lex Cornelia testamentaria nummaria, cuyo texto no nos es conocido de forma directa, sino por referencias posteriores, esto es a través de otros textos legales, que bien pueden ser exactos, o bien pueden haber sufrido interpolaciones ${ }^{1}$.

A la regulación de la falsedad documental se llega a través de la evolución experimentada a partir de un supuesto concreto, esto es, el de falsedad testamentaria. Esta circunstancia exige que el estudio de esta temática deba comenzar refiriéndonos a aquel punto de partida y a la ley que lo regula ${ }^{2}$. Sin embargo, hay que decir que, antes de la citada ley, la falsedad testamentaria debió de ser también objeto de sanción, aunque por una vía distinta. No regulada por ninguna ley especial, sólo podía ser perseguida, como apunta Mommsen ${ }^{3}$, por uno de estos dos medios: invocando el vago concepto de los delitos contra el Estado o bien aplicándole por interpretación extensiva alguna de las leyes especiales publicadas para otro tipo de actuaciones.

1 Cf. Alejandre García, «Estudio histórico del delito de falsedad documental». AHDE, 42 (1972), 126.

${ }^{2}$ La romanística le ha prestado escasa dedicación; no obstante, podemos referirnos a algunos estudios que tratan directamente esta materia, entre otros: ARCHI, «Problemi in tema di falso nel diritto romano», en Scritti di diritto romano, vol. III (Milano, 1981), 1487-1587; D’Ors, A., «Contribuciones a la historia del Crimen falsi», en Studi in onore di Edoardo Volterra, II (Milano, 1971), 537-558; AlEJANDRE GARCÍA, J.A., «Estudio histórico del delito de falsedad documental», 117-187, dedica el autor citado un apartado al sistema romano visigodo de la regulación de la falsedad documental.

${ }^{3}$ Mommsen, T., Derecho penal romano. Trad. del alemán por P. Dorado (Bogotá, 1976), 420. 
Por otra parte, también se ha de destacar que la Lex Cornelia primitiva sancionaba la falsedad del testamento, tal vez por las razones que más adelante tendremos ocasión de explicitar. A partir de este supuesto concreto del tratamiento legal de la falsedad testamentaria, la regulación se extiende a otros supuestos en los términos que veremos en los siguientes apartados. Como consecuencia de esta generalización se deduce que el testamento deja de ser el núcleo fundamental de la falsedad para diluirse o subsumirse bajo el régimen jurídico-penal general de la falsedad documental. Puede dar la impresión de una falta de unidad en el tipo delictivo, pues los supuestos que subentran en el falsum ${ }^{4}$ parecen muy dispares aunque el examen de ese cuadro variado con un criterio histórico permite entrever la lógica interna de tal desarrollo ${ }^{5}$.

En las presentes líneas nos vamos a referir, en primer lugar, a una serie de disposiciones del derecho romano que regulan la materia objeto de estudio, esto es, disposiciones contenidas en las Sentencias de Paulo $^{6}$, así como en la Collatio Legum ${ }^{7}$. También determinados textos del Digesto de Justiniano y constituciones del Código del citado emperador tienen relación con la materia aquí tratada. Pero, además, van a ser objeto de nuestra atención las disposiciones acerca de la falsedad documental en la legislación visigoda, básicamente determinadas disposiciones contenidas en la Lex Visigothorum 7,5, títulus: de falsariis scripturarum; al final de cada disposición de la LV se incluye la versión de la misma contenida en el Fuero $\mathrm{Juzgo}^{8}$.

${ }^{4}$ Un punto que tradicionalmente ha planteado la doctrina, es la concurrencia entre el falsum y el stellionatus, vid. MentXaKA, R., «Stellionatus» en Bulletino dell'Istituto di Diritto Romano, Vol. XXX, (1988), 334. La autora después de realizar el análisis de los textos que tienen relación con el estelionato, establece que «en ningún momento se expone un supuesto de hecho en el que los juristas debatan sobre si el caso planteado puede ser calificado de falso o de estelionato». Es cierto que algunos textos del Digesto y del Código de Justininano (D. 48.10 .21 ; D. $48,10,28$ y C. $9,22,15$ ) presentan ciertas actividades fraudulentas realizadas por el deudor, por ejemplo, la doble venta de un mismo objeto a dos compradores o la mentira de un deudor sobre la fecha de una hipoteca, estos casos podían ser calificados como crimen falsi. Ello plantea el problema, sigue diciendo la autora citada, de determinar si ciertos supuestos podían dar lugar a una concurrencia entre el falsum y el estelionato, Ibidem.

5 Cf D'Ors, «Contribuciones a la historia del crimen falsi», Studi in onore di Edoardo Volterra, II (Milano, 1971), 544.

${ }^{6}$ Las Pauli Sententiae son citadas en la edición propuesta en Fontes Iuris Romani Anteiustiniani, FIRA. Vol. I, Leges. ed. S. Riccobono (1941, nueva ed. 1968); II Auctores, de I. Bavier e I. Furlani (1940, nueva de 1964), III Negotia, de V. Arangio Ruiz (1943, nueva ed. con apéndice, Florentiae, 1968).

7 Se trata de un texto legal, obra de un autor anónimo que, como es sabido, compara textos mosaicos y textos de juristas romanos. Edición FIRA.

${ }^{8}$ La compilación legislativa promulgada por Recesvinto y cuya fecha de promulgación se suele colocar en el año 654 se la conoce por los diferentes nombres de Lex Visigo- 


\section{Regulación romana}

\subsection{Consideraciones generales}

En primer lugar se ha de decir que en el ámbito del antiguo derecho penal la Lex Cornelia testamentaria nummaria, sobre los testamentos y las monedas (citada supra), dada por Sila, se dirigía contra una serie de actos relacionados con las falsedades. La jurisprudencia de los tiempos posteriores agrupó bajo la palabra falsum, en el lenguaje moderno, falsificación, una serie de hechos delictuosos sancionados por la citada ley y por las sucesivas ampliaciones que se hicieron más adelante de la misma. Hay que tener en cuenta que disposiciones de carácter general en relación con ello no se promulgaron antes de Sila. Por otra parte, «parece que no es posible formar un concepto único del delito, aplicable a todos los hechos comprendidos en la ley y en las aplicaciones que se hicieron de la misma; de suerte que la falsificación no es en el derecho romano una idea unitaria más que desde el punto de vista del procedimiento y para los efectos procesales» ${ }^{9}$.

\subsection{Regulación primitiva: la Lex Cornelia testamentaria, nummaria}

La citada ley se denominaba así por referirse a la falsificación de testamentos y monedas, testamentaria nummaria. Las fuentes la designan en otras ocasiones, Lex Cornelia de testamentis y Lex Cornelia de falsis, aunque esta última designación correspondería a una época posterior.

Con relación a la fecha de la citada ley, en la actualidad parece aceptarse el año 81 a.C., con lo que resultaría coetánea de otra ley Cornelia contra sicarios y envenenadores ${ }^{10}$.

Por lo que se refiere a la cuestión de la sucesión en el contexto romano, inicialmente la forma más frecuente era generalmente $a b$ intestato, o bien en el caso de sucesión testada, el testamento tenía lugar en presencia del pueblo, era el llamado testamento calatis comitiis, o tenía lugar bajo la fórmula per aes et libram; además, otra forma de testamento era el realizado por el soldado ante el ejército en armas, esto es,

thorum, Liber Iudiciorum o Liber Iudicum; debe destacarse, además, que la citada compilación se traduce al castellano en el Siglo XIII con el nombre de Fuero Juzgo. Fuero Juzgo, en Códigos Antiguos de España, ed. M. Martínez Alcubilla (Madrid, 1885).

9 Mommsen, T., Derecho penal romano, 418. Sobre el particular, ver D’ORs, «Contribuciones a la historia del crimen falsi», Studi in onore di Edoardo Volterra, II (Milano, 1971), 544, se refiere a la falta de unidad en el tipo delictivo de la falsedad. AlEJANDrE GARCíA, «Estudio histórico del delito de falsedad documental», AHDE, 42 (1972), 126 ss.

10 Lex Cornelia de sicariis et veneficiis, vid. PS 5,23; D. 48,8; C. 9, 16. 
el testamento in procintu. En todos estos casos citados el testamento no era fácilmente falsificable. Más adelante, surgen nuevas formas de testar, entre ellas el testamento escrito, y por tanto mucho más fácil de falsificación ${ }^{11}$. Es esta la nueva situación en la que tiene lugar la publicación de la Lex Cornelia sobre falsificaciones.

Concretamente se refiere Mommsen a las causas probables que dieron motivo a la regulación de las falsificaciones en el derecho romano. Es de presumir, según el citado autor ${ }^{12}$, que la ley dada por Sila contra los sicarios y los envenenadores fuese provocada por la frecuencia con que se cometían tales delitos en aquellos agitados y desenfrenados tiempos, y es también probable que las mismas causas determinasen la publicación de la Lex Cornelia testamentaria nummaria, que solía denominarse lex Cornelia testamentaria y después se llamó Lex Cornelia de falsis. Hay que tener en cuenta que mediante la citada ley quedaron sometidos a un procedimiento fijo y a penas legales una serie de acciones que hasta la fecha de la misma no podían ser perseguidas sino, en todo caso, invocando medios indirectos ${ }^{13}$.

Así pues, la Lex Cornelia testamentaria nummaria se refería a la falsificación de testamentos y monedas, testamentaria nummaria, pero acabó por llamarse de falsis, por el amplio campo de aplicación que llegó a alcanzar $^{14}$.

\subsubsection{Tipos delictivos que establece la ley}

En cuanto a los tipos delictivos la citada ley había previsto, en primer lugar, distintos tipos de falsedad en relación con los testamentos, así el texto de Paulo de los Comentarios a Sabino, libro III, en D.48,10,2, establece lo siguiente: qui testamentum amoverit, celaverit, eripuerit, deleverit, interleverit, subiecerit, resignaverit, quive testamentum falsum scripserit, signaverit, recitaverit dolo malo cuiusve dolo malo id factum erit, legis Cornaliae poena damnatur. Como se acaba de ver, distinguía la ley una serie de actos, concretamente, hacer (scribere) o sellar (signare) ${ }^{15}$ un testamento falso o hacer uso judicial del mismo (recitare). También se

11 AlEJANDRE, «Estudio histórico ...», 129.

12 Mommsen, Derecho penal romano, 420.

13 Sobre el particular, cf. la nota 3.

14 D'Ors, «Contribuciones ... », 544. También se refiere el autor citado a los lugares donde aparece la designación, testamentaria nummaria, 544, nota 52.

15 Los tres verbos aparecen en D.47,11,6, 1, donde se establece: Onerant annonam etiam staterae adulterinae, de quibus Divus Trainus Edictum poposuit, quo Edicto poenam legis Corneliae in eos statuit, perindae ac si lege testamentaria, quod testamentum falsum scripsisset, signasset, recitasset damnatus esset. 
refiere el citado texto a otros actos dolosos relativos a un testamento auténtico, así, sustraerlo (amovere), ocultarlo (celare), robarlo (eripere), destruirlo (delere) y alterar su escritura (interlinere), cambiarlo por otro (subicere) o abrirlo indebidamente (resignare). En parecidos términos, una serie de actos delictivos son penados por la ley Cornelia en las Pauli Sententiae 4,7,1, donde se establece concretamente lo siguiente: qui testamentum falsum scripserit, recitauerit, subiecerit, signauerit, suppreserit, amouerit, resignauerit, deleuerit, poena legis Corneliae de falsis tenebitur. Asimismo, en PS 5,25,1, castigaba la ley la falsificación de sellos en general (signum adulterinum) distinguiendo por una parte, el esculpir su cuño (sculpere), hacerlo (facere $)^{16}$ y extraer el sello del cuño (exprimere).

Otro tipo de acto delictivo lo tenemos en PS 5,25,717 donde se alude a la manipulación fraudulenta en un testamento auténtico, en este caso, perteneciente a una persona viva, en los siguientes términos: qui uiui testamentum aperuerit recitauerit resignauerit poena legis Corneliae tenetur.

Por otra parte, hemos de decir que el citado texto de las PS 5,25, $1^{18}$ hace referencia asimismo a distintos tipos de actos relacionados con las monedas, así como la suposición falsa de parto ${ }^{19}$, que no son objeto de estudio en las presentes líneas. La asociación en una misma ley de la falsificación de testamentos, de sellos y de monedas es muy explicable: el elemento común era el abuso del signum ${ }^{20}$.

\subsubsection{Aplicación extensiva de la Lex Cornelia por medio de senadoconsultos}

La expansión de la ley a nuevos supuestos se realiza mediante la aplicación de la poena legis Corneliae que hicieron algunos senadoconsultos ${ }^{21}$ y que tienen relación con una progresiva ampliación del falsum. Así, concretamente el SC Liboniano del año 16 d. C., tuvo más importancia

16 Ver D. 48,10,30 pr.: Lege Cornelia testamentaria obligatur, qui signum adulterinum fecerit, sculpserit.

17 PS 5,25,7: Qui uiui testamentum aperuerit recitauerit resignauerit, poena legis Cornaliae tenetur; et plerumque aut humiliores in metallum dantur aut honestiores in insulam deportantur.

18 PS 5,25,1,1. Qui falsam monetam percusserint, si id totum formare noluerant, suffragio iustae paenitentiae absoluuntur.

19 PS 5,25,1,1b. Accusatio suppositi partus nulla temporis praescriptione depellitur, nec interest, decesserit nec ne ea quae partum subdidisse contenditur.

20 Cf. D'Ors, «Contribuciones a la historia del crimen falsi », 546.

21 Se trata de los senadoconsultos Liboniano, Mesaliano y Geminiano, sobre los cuales realizó D'Ors un cotejo textual que expuso en una sesión del «Circulo Toscano» de Florencia. Posteriormente el citado autor, se refiere de nuevo a los tres senadoconsultos mencionados, en el artículo «Contribuciones a la historia del crimen falsi», 527 ss. 
para toda la materia documental que los otros senadoconsultos ${ }^{22}$ (SC Mesaliano y Geminiano) también relativos al falsum y por esto Paulo le dedicó un tratamiento que pudo ser editado como monografía independiente $^{23}$. Una referencia expresa al mismo (al SC Liboniano) la tenemos en el Digesto de Justiniano, donde precisamente la rúbrica de D.48,10, reza en los siguientes términos: De lege Cornelia de falsis et de senatusconsulto Liboniano. El citado senadoconsulto añade a los supuestos punibles anteriores, el consistente en la atribución a sí mismo por el escriba de un legado en provecho propio, y de esta forma tenemos que en C.9,23, $3^{24}$ se imponía la pena de la ley Cornelia como falsario, al scriptor de un testamento que se otorgaba en él una institución como heredero o legatario; además, no se exceptuaba para estos casos el testamento militar, según se establece en D.48,10,1,725.

Parece lo más probable que este senadoconsulto, que amplía la aplicación de la Lex Cornelia testamentaria, es el mismo al que se refiere Ulpiano en el texto legal Collatio Legum 8,726. El romanista D'Ors ${ }^{27}$ extiende más esta identificación, concretamente al texto contenido en PS 5,25,6.

22 El sc. Mesaliano sometía a la pena de la ley Cornelia a los que cobraban, pactaban o se asociaban para complicar en los procesos a personas inocentes. Por otra parte, el sc. Geminiano sometió a la misma pena a los que cobraban por citar, no citar o despedir a un testigo ya citado, así como a los testigos que cobraban por declarar o no su testimonio: se penaba la venalidad, independientemente de la fasedad.

23 Cf. D’Ors, «Contribuciones... », 533.

${ }^{24}$ El rescripto del emperador Alejandro en C.9,23,3, establece lo siguiente: Senatusconsulto et edicto divi Claudii prohibitum est, eso qui ad scribenda testamenta adhibentur, quamvis dictante testatore, aliquod emolumentum ipsis futurum scribere. Et poena legis Corneliae facienti irrogata est, cuius veniam deprecantibus ob ignorantiam, et profitentibus a relicto disceder, amplissimus ordo vel divi principes veniam raro dederant. Las disposiciones testamentarias a favor del escriba se tenían por no escritas, cf. D.34,8,1. También en D.27,2,29 se establece que por disposición del senadoconsulto Liboniano no será tutor el que a sí mismo se escribió en un testamento tutor de un pupilo.

25 D. 48,10,1,7, donde se dispone lo siguiente: Ad testamenta militum Senatusconsultum pertinet, quo lege Cornelia tenentur, qui sibi legatum fideicommissumve adscripserint.

${ }^{26}$ Coll. Legum 8,7, recoge un texto de Ulpiano, correspondiente al libro octavo de officio proconsulis, que bajo el título de poena legis Cornaliae testamentariae, establece lo siguiente: 1. Praeterea factum est senatusconsultum Statilio et Tauro consulibus, quo poena legis Corneliae inrogatur ei, qui quid aliud quam testamentum sciens dolo malo falsum signauerit signariue curauerit, item qui ad falsas testationes faciendas testamentaue falsa inuicem dicenda aut consignanda dolo malo coierint, Licinio V et Tauro conss.

27 D'Ors, «Contribuciones ...», 532: al senadoconsulto por el que amplissimus ordo decrevit eas tabulas quae publici uel priuati contractus scripturam continent, adhibitis testibus ita signari, ut in summa marginis ad mediam partem perforatae triplici lino constringantur atque impositae supra linum cerae signa imprimantur, ut exteriori scripturae fidem interior seruet: aliter tabulae prolata nihil momenti habent (PS 5,25,6). Contra la identificación de este senadoconsulto con el Liboniano está la atribución a Nerón en SuETONIO, Nero, 17. 
Por otra parte, hay que decir también que parece seguro que dicho senadoconsulto inicia la expansión de la Lex Cornelia a ciertos documentos no testamentarios. Así, podemos citar el texto de D.48,10,16,1, donde se establece lo siguiente: Paulo respondió que están sujetos a la pena de la ley Cornelia todos los que hubiesen signado otras cosas falsas aunque no sean testamentos, omnes qui etiam extra testamenta cetera signassent.

Además, como consecuencia de los textos que nos informan acerca del citado senadoconsulto, puede decirse que el mismo no alcanza a todo tipo de documentos falsos, sino que quedó reducido a los documentos cum consignatione; de manera que no preveía otro tipo de documentos en los que faltaban los signa y que, por otra parte, eran cada día más frecuentes. Esta laguna fue cubierta por una extensión a esos documentos sine consignatione de la que nos informan el jurista Marciano en un texto contenido en D.48,10,1,4 ${ }^{28}$ y Paulo en D.48, 10, 16, $2^{29}$. En el primer texto, Marciano cita un rescripto de Septimio Severo que, según $\operatorname{Archi}^{30}$, sería el que habría introducido la nueva extensión del senadoconsulto.

El supuesto principal, aunque no único, de esta serie de documentos sine consignatione debía de ser el de la documentación burocrática $\mathrm{y}$, concretamente, el rescripto del emperador Severo en el citado texto de D.48,10,1,4 es un ejemplo. Los textos de Paulo y Marciano citados supra no se refieren al album propositum, pero podemos aludir a un texto de Modestino en D.48,10,32, pr., donde establece precisamente lo siguiente: hodie qui edicta perpetua dolo malo corrumpunt falsi poena plectuntur $^{31}$. Por otra parte, la falsificación del album propositum se regula en PS 5,25,5, cuando establece: qui rationes acta libellos album propositum testationes cautiones chirographa epistulas sciens dolo malo in fraudem alicuius deleuerit mutauerit subiecerit subscripserit, quiue aes inaurauerit argentauerit, quiue, eum argentum aurum poneret,

28 D. 48,10,1,4: Qui in rationibus, tabulis cereisve, vel alia qua re sine consignatione falsum fecerint, vel rem amoverint, perinde ex his causis, atque si erant falsarii, puniuntur; sic et Divus Severus lege Corneliae de falsis damnavit praefectum Aegypti, quod instrumentis suis, quum praeerat provinciae, falsum fecit. El texto de Marciano parece resumir lo que se detalla en el texto de Paulo, citado en la nota siguiente.

29 D. 48,10,16,2, establece: sed et ceteros, qui in rationibus, tabulis, literis publicis, aliave qua re sine consignatione falsum fecerunt, vel $u t$ verum non appareat, quid celaverunt, surripuerunt, subiecerunt, resignaverunt, eadem poena affici solere, dubium non esse.

30 ARCHI, «Problemi in tema di falso nel diritto romano», Scritti di diritto romano (Milano, 1981), 1506.

31 El citado jurista en el mismo libro de las Penas, 1, contenido en D. 48,10,32,1 alude a un decreto del emperador Adriano que establecía la pena de destierro en una isla para los que hubiesen falsificado pesos o medidas. 
aes stannumue subiecerit, falsi poena coercetur. De manera que la falsificación del album propositum es objeto de sanción con la pena de la ley Cornelia, al igual que otra serie de documentos a los que se refiere el texto que acabamos de citar.

Otra ampliación de la pena de falsedad tiene lugar en un texto de Marciano; en este caso en D.48,10,1,932, el citado jurista, se remite a los rescriptos de los emperadores Severo y Antonino que extienden la sanción a los supuestos de fraude en la rendición de cuentas por parte de los tutores y curadores. La generalización de la falsedad de documentos la encontramos en PS $5,25,1^{33}$ donde son sancionados con la pena de la Lex Cornelia: qui testamentum quodue aliud instrumentum falsum sciens dolo malo... Una mayor explicitación en PS 5,25,9 sancionando con la misma pena: qui falsis instrumentis actis epistulis rescriptis sciens dolo malo usus fuerit.

Asimismo, la ampliación del sc Liboniano tiene relación con una serie de actos en $E d$. Theod. $90^{34}$ que se añaden a los actos contenidos en PS 5,25,5, esto es a los verbos delere, mutare, subicere y subscripsere,

32 D. 48,10,1,9, establece: Ex illa quoque causa falsi poenae quis subiicitur ut Divi quoque Severus et Antoninus constituerunt, ut tutores et curatores, et qui officio deposito non restituerunt tutelam vel curationem, cum fisco contrahere non possint, ac si quis adversus hanc legem profectus aerario obrepserit, ut perinde puniatur, ac si falsum commisisset.

33 En las Pauli Sententiae 5,25,1, alude el texto legal a una serie de actos dolosos relacionados con el testamento u otro tipo de documento en los siguientes términos: Lege Cornelia testamentari \{tenentur:\} qui testamentum quodue aliud instrumentum falsum sciens dolo malo scripserit recitauerit subiecerit suppresserit amouerit resignauerit deleuerit, quodue signum adulterinum sculpserit fecerit expresserit amouerit reserauerit...

34 El Edictum Theodorici es una colección de 155 capítulos breves que tratan materias de derecho privado, derecho penal y procesal (y probablemente para una zona en conflicto). El Edicto se basa en fuentes romanas, en concreto las Pauli Sententiae y códigos Gregoriano, Hermogeniano y Teodosiano. Se ha afirmado que el derecho romano que contiene es más puro que el del palimpsesto de París, por lo que se puede decir que pertenece a los cuerpos legales que, como la Lex Romana Visigothorum o la Lex Romana Baiuvariorum, son colecciones de derecho romano emanadas en los reinos germánicos que ocuparon la mitad occidental del Imperio. Sin embargo, sigue siendo hasta el presente un problema abierto la autoría de este Edictum. Tradicionalmente se atribuía a Teodorico el Ostrogado (493-526) pero la teoría se puso en cuestión a mediados del siglo XX. RASI, «Sulla paternità del c.d. edictum Theodorici regis», en Archivio Giuridico, 145 (1053), 115 ss., fue el primer autor que en 1953 llamó la atención sobre el tema; más adelante, fue VISMARA, G., «El Edictum Theodorici», en Cuadernos del Instituto Jurídico Español, 5. Estudios Visigóticos I (Roma-Madrid, 1956), 49-89, quien identificó el citado texto legal con las leyes de Teodorico II (453-466), rey de los visigodos y antecesor de Eurico, manteniendo además que el Edicto recogía el ambiente de las Galias del siglo v. Pithou publicó por primera vez el texto del Edicto en 1579 y al parecer utilizó para ello dos códigos franceses hoy perdidos. Utilizó la edición de FIRA. Existe además la edición de F. BLumE, MGH, LL, 5. Sobre este Edicto ver BECKER, H.J., «Edictum Theodorici», en HRG, 1, 802-803. 
sobre determinados documentos, se añaden en el Edicto citado los actos relativos a incendere y radere ${ }^{35}$.

En definitiva, como decíamos arriba el senadoconsulto Liboniano tenía inicialmente relación con los documentos con signa, pero la ampliación posterior del mismo los equipara con los documentos sine consignatione a los efectos de sancionar cualquier abuso de los mismos ${ }^{36}$.

\subsection{Posibles abusos relacionados con los documentos}

En cuanto a los posibles abusos pueden distinguirse fundamentalmente, el uso de documentos falsos y la sustracción de un documento auténtico.

En primer lugar, por lo que se refiere a la recitatio de documentos falsos, para que esta fuese punible, debía tratarse de una recitatio dolosa, así en PS 5,25,9 cuando establece: qui falsis instrumentis actis epistulis rescriptis sciens dolo malo usus fuerit, poena falsi coercetur. Es cierto que algunos rescriptos imperiales establecían matizaciones, podemos citar concretamente, un rescripto de Antonino Pío en D.48,10,3137, donde se regula que la presentación de documentos falsos debía castigarse según la importancia de cada delito y en otro de los emperadores Marco Aurelio y Vero ${ }^{38}$ se establece el perdón de quienes presentasen a juicio documentos falsos sin saberlo. Por otra parte, el texto de Papiniano en D.48,10,13,139 establece que no se incurre en la ley Cornelia por haber recitado una falsedad, no habiéndola cometido.

35 Ed. Theod. 90: Qui testamentum, codicillum, tabulas, rationes, gesta, libellos, cautiones, epistolas in froudem alterius, quocumque loco deleuerint, mutauerint, subiecerint, subrepserint, incenderint, raserint .... poenam sustineant falsi crimini constitutam. Se cita el Edicto de Teodorico por la edición Fira.

36 Cf. D’ORs, «Contribuciones ...», 549-50.

37 El texto de Callistratus en el libro III de Cognitionibus, contenido en D. 48,10,31, establece lo siguiente: Divus Pius Claudio rescripsit, pro mensura cuiusque delicti constituendum in eos, qui apud iudices instrumenta protulerunt, quae probari non possint; aut si plus meruisse videatur, quam ex forma iurisdictionis pati possint, ut Imperatori describatur aestimaturo, quatenus cerceri debeant....

38 En el mismo texto de Callistratus, asimismo en D. 48,10,31, se establece: Sed Divus Marcus cum fratre suo pro sua humanitate hanc rem temperavir, ut, si, quod plerumque evenit, per errarom huismodi instrumenta proferantur, ignoscatur iis, qui tale quidquam protulerint.

39 El texto del jurista Papiniano correspondiente al libro XV, Responsorum, contenido en D. 48,10,13,1, establece lo siguiente: Ordine decurionum decem annis advocatum motum, qui falsum instrumentum cognoscente Praeside recitavit, post finem temporis dignitatem respondi recuperare, quoniam in Corneliam falso recitato, non facto, non incidit; eadem ratione plebeium ob eandem causam exilio temporario punitum decurionum post reditum recte creari. 
Otros textos aluden al uso de documentos sine consignatione. Precisamente un rescripto de Alejandro Severo en C.9,22,340 se refiere a la severidad que merece el uso de rescriptos falsos; por otra parte, un texto del jurista Modestino en D.48,10,33 ${ }^{41}$ aclara que el uso de constituciones falsas implica la sanción de la ley Cornelia. Hemos de decir asimismo que un tipo especial de uso de documentos falsos tiene relación con la ostentación de diplomas falsos. Así, concretamente, el texto de Modestino en D.48,10,27, $2^{42}$ se refiere al que falso diplomate vias commeavit, pero generaliza la tipificación criminal a todo aquel que: se pro milite gessit, vel illicitis insignibus usus est. También en PS 5,25,12 se establece: qui insignibus altioris ordinis utuntur militiamque confingunt, quo quem terreant uel concutiant. Otras modalidades sancionadas por la ley Cornelia tienen relación con el uso de nombres o parentescos falsos en PS 5,25,1143, así como también la ostentación de amistades judiciales, PS 5,25,1344.

Por lo que se refiere a la subreptio de documentos auténticos la ley Cornelia preveía la sanción para la sustracción de un testamento auténtico, pero el sc Liboniano no había extendido esa sanción a la sustracción de otro tipo de documentos. Un texto de Paulo en D. 48,10,16, $\mathrm{pr}^{45}$ establece expresamente que el iudicium publicum sólo podía darse por sustracción de testamentos. Sin embargo, el mismo jurista en D. $48,10,16,2^{46}$ nos dice que la pena de la ley Cornelia se aplica a los que sustrajeron cualquier clase de documento. Por lo tanto, no hay contradicción, sino referencia a la sanción que tiene lugar por vía de la

40 C. 9,22,3: Licet ex tabulis, quas sub nomine patris tui uxorem eius, id est novercam tuam, subrepto vero testamento, falsas protulisse allegas, quum crimen admissum ignorares, legatum adscriptum tibi consecutus sis, tamen non impedieris accusationem contra eam, impletis solemnibus, instituere.

${ }^{41}$ El texto de Modestino en el libro III de Poenis, en D. 48,10,33: Si quis falsis Constitutionibus nullo auctore habito utitur, lege Cornelia aqua et igni ei interdicitur.

42 El texto del jurista Modestino del libro VIII, Regularum, contenido en D. 48,10 27,2, dice lo siguiente: Qui se pro milite gessit, vel illicitis insignibus usus est, vel falso diplomate vias commeavit, pro admissi qualitate gravissime puniendus est.

43 PS 5,25,11, establecen: Qui sibi falsum nomen imposuerit, genus parentesue finxerit, quo quid alienum interciperet caperet possideret, poena legis Corneliae de falsis coercetur.

${ }^{44}$ En relación con este punto, en PS 5,25,13, se establece: Si qui de iudicis amicitiis uel familiaritate mentientes euentus sententiarum euis uendunt, quidue obtentu nominis eius agunt, conuicti pro modo delicti aut relegantur aut capite puniuntur.

45 D. 48,10,16.pr.: Instrumentorum subreptorum crimen non esse publici iudicci, nisi testamentum alicuius subrreptum arguatur.

46 D. 48,10,16,2: Sed et ceteros, qui in rationibus, tabulis, literis publicis, aliave qua re sine consignatione falsum fecerunt, vel ut verum non appareat, quid celaverunt, surripuerunt, subiecerunt, regnaverunt, eadem poena affici solere, dubium non esse. 
cognitio $^{47}$.Otro texto, en este caso de Marciano, en D.48,10,1,648 admite la extensión del falsum al caso de abuso de confianza del depositario de documentos si los revela al representante del depositante. En PS 5,25,8 ${ }^{49}$ y D. 48,19,38,8 $8^{50}$ la extensión del falsum al hurto de documentos tiene lugar por el abuso por parte de un depositario representante procesal (bien se trate de un procurator o de un cognitor, como hemos visto en las Sentencias de Paulo). Además, los textos de PS $5,25,10^{51}$ y de D.48,19,38,952 se refieren al abuso de los documentos por parte de un depositario cualquiera.

También se ha de decir que, probablemente, la inclusión de la $s u$ breptio de cualquier documento dentro del falsum se reducía a aquellos casos en que se trata de dificultar una prueba, como dice Paulo en D. 48,10,16,253: ut veram non appareat, o como se establece en el Edicto de Teodorico, $90^{54}$ in fraudem alterius; en otros casos, el hurto no quedaría criminalizado.

47 Sobre la evolución del derecho penal romano, ver: ARANGIO-RuIZ; GuARINO; PUGLIESE, Il diritto romano, (Roma, 1982), 249 ss. Avonzo, F., «Coesistenza e connessione tra iudicium publicum e iudicium privatum», en BIDR, LV-LVI, 1956, 125 ss.; BRASIELLO, U., «Sulle linee e i fattori dello sviluppo del diritto penale romano», en $A G$, CXX, 1938, 3 ss.; IDEM, «Crimi-

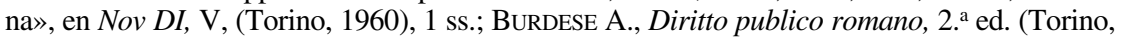
1975), 225 ss.; Costa, E. Crimini e pene da Romalo a Giustiniano, (Bologna, 1921), 148; FACHI, G.F., Diritto penale romano (dottrine generali), (Treviso, 1930), 235; Mommsen, T., Derecho Penal romano, dedica el cap. V, 37 ss. a la evolución del derecho penal romano PugLiESE, G., «Linee generali dell'evoluzione del diritto penale publico durante il principato», en $A N R W$, II. 14 (Berlin-New York, 1982), 727 ss. Thomas, J.A.C., «The Development of Roman Criminal Law», en LQR, LXXIX, 1963, 224 ss. y en AHDE, XXXII, 1962, 7 ss.

48 D. 48,10,1,6, establece: Is, qui deposita instrumenta apud alium ab eo prodita esse adversariis suris dicit, accusare eum falsi potest.

49 El texto de las Pauli Sententiae establece lo siguiente: Si quis instrumenta litis suae a procuratore uel cognitore aduersario prodita esse conuicerit, tam procurator quam cognitor, si humiliores sunt, in metallum damnatur, si honestiores sunt, adempta dimidia parte bonorum in perpetuum relegantur.

${ }^{50}$ Si quis instrumentum litis suae a procuratore adversario proditum esse convicerit, procurator, si humilior sit, in metallum damnatur, si honestior, adempta parte bonorum dimidia in perpetuum relegatur.

${ }^{51}$ Establece el texto de las Pauli Sententiae 5,25,10 lo siguiente: Instrumenta penes se deposita quicumque alteri altero absente reddiderit uel aduersario prodiderit, pro personae eius condicione aut in metallum damnatur aut in insulam relegatur.

${ }^{52}$ El texto de Paulo del libro V. Sententiarum, recogido en D. 48,19,38,9, casi en los mismos términos dispone que: Instrumenta penes se deposita quicunque alteri altero absente reddiderit, vel adversario prodiderit, prout personae conditio est, aut in metallum damnatur, aut in insulam deportatur.

53 D. $48,10,16,2$, ver el contenido del texto en la nota 46.

54 Edictum Theodorici, 90: Qui trestamentum, codicillium, tabulas, rationes, gesta, libellos, cutiones, epistolas in fraudem alterius, quocumque loco deleuerint, mutauerint, subiecerint, subrepserint, indenderit, raserint, aut aes, argentum, uel ferrum inauratum scientes pro auro dederint, uel uendiderint, uel subposuerint, quique pro argento stamnum 
Finalmente, un texto de Ulpiano en el libro 9 de off. proc. en D. $47,11,8^{55}$ nos informa que la executio para este tipo de abuso documental fue dada por Marco Aurelio y Vero a la jurisdicción del praefectus urbi; según D'Ors, esto nos da una posible fecha del momento en que se produjo le extensión del falsum al abuso documental fuera de los testamentos ${ }^{56}$.

\subsection{Las penas establecidas por la ley}

La pena señalada por la ley fue primeramente la muerte, aunque desde fines de la República, se aplicaba ya la interdictio aqua et igni, que se entiende después como deportación y confiscación de los bienes para los honestiores, o condena ad metalla o cruz para los humiliores; además, la muerte para los esclavos manumitidos después del delito ${ }^{57}$.

Mencionamos a continuación algunos textos que aluden expresamente a las sanciones que imponía la lex Cornelia de falsis. En primer lugar, en el texto contenido en PS 4,7,1, después de referirse a una serie de actos delictivos relacionados con el testamento, se establece lo siguiente: poena legis Corneliae de falsis tenebitur, id est in insulam deportatur. La misma ley anterior (La Lex Cornelia de falsis), llamada ahora Lex Cornelia testamentaria en el citado texto legal de las PS 5,25,1, establece lo siguiente en relación con las penas: ... honestiores quidem in insulam deportantur, humiliores autem aut in metallum dantur aut in crucem tolluntur; serui autem post admissum manumissi capite puniuntur. Se tienen aquí en cuenta las circunstancias subjetivas que pudieran concurrir en el autor.

Por otra parte, son muchos los textos del Digesto de Justiniano que al referirse a la falsificación de documentos, establecen para esos supuestos la pena de la Lex Cornelia ${ }^{58}$. Otros textos hacen expresa mención al tipo

subiecerint, uel exteriorem circulum solidi praeciderint, quiue, ut id fieret, iusserint operamue dederint, poenam sustineant falsi crimini constitutam.

55 D. 47,11,8, establece: Sunt praeterea crimina, quae ad executionem Praesidis pertinent, utputa si quis instrumenta sua prodita esse dicat; nam huius rei executio Praefecto urbis a Divis fratribus duta est.

56 Cf. D’ORs, «Contribuciones ...», 552.

57 Vid. ARCHI, «Problemi in tema di falso...», 1492 ss. Hay divergencias en la interpretación de los textos de Paulo en las PS. El autor citado que sigue fundamentalmente a LEVY en este punto, considera que la pena señalada por la ley fue primeramente la muerte; a fines de la República se admitía la alternativa entre la muerte y el exilio; en la época de los juristas Marciano y Ulpiano la pena del falso era la deportación. Por el contrario, Brasiello, considera que debió de ser aplicable durante toda la época clásica la interdictio aqua et igni, sustituyendo a la pena de muerte a fines de la República, Ibidem, nota 15.

58 Sobre el particular, ver, entre otros: D. $34,8,1$; D. 48,10,2; D. 48,10,9,3; D. 48,10,13, pr.; D. 48,10,16, 1 y 2; D. 48,10,32; asimismo, en C. 9,23,3 . 
de sanción impuesta por la mencionada ley. Podemos referirnos concretamente a determinados textos: D. 48,19,38,8, donde se alude a la siguiente sanción: si humilior sit, in metallum damnatur, si honestior, ademta parte bonorum dimidia in perpetuum relegatur; También D.48,19,38,9, prout personae conditio est, aut in metallum damnatur, aut in insulam deportatur; asimismo en D. 48,10,33, acerca del uso de constituciones falsas, se impone: lege Cornelia aqua et igni ei interdicitur.

\section{Derecho visigodo ${ }^{59}$}

\subsection{Lex Visigothoram ${ }^{60}$}

Una vez analizada la regulación jurídica romana relativa a la falsedad de los documentos y las penas correspondientes establecidas en la ley Cornelia, nos centramos seguidamente en la legislación de los visi-

\footnotetext{
59 El reino visigodo, antes de su establecimiento definitivo en Occidente, se constituyó en estrecha relación con el Imperio, al que desde antiguo venía prestando servicios militares de frontera bajo la fórmula del foedus (cf. RAFAEL GIBERT, «El reino visigodo y el particularismo español», en Cuadernos del Instituto Jurídico Español, 5. Estudios visigóticos, I (Roma-Madrid, 1956), 17 y las notas 6 y 7. El primer período del asentamiento de los visigodos en las Galias y en la parte noroeste de la Península, dominio que por el occidente llegó al parecer hasta Zaragoza, se inscribe en la estructuración del Imperio romano, en la etapa anterior a la caída de Roma por los hérulos (cf. entre otros, OrLANDIs, J., Historia de España. La España visigótica (Madrid, 1977), 59 ss. García GALlo, A., «Consideración crítica de los estudios sobre la legislación y la costumbre visigodas», en AHDE, (1974), 424 ss.). A partir del año 476, con la entrada de Odoacro en Roma, la situación sufrió transformaciones profundas que se manifestaron de forma desigual en los distintos territorios sobre los que estaban asentados los visigodos. Durante esta época perdura la misma estructura territorial y política y al mismo tiempo los órganos de la administración romana continúan desarrollando las funciones de gobierno, con cierta intervención de los monarcas visigodos. Con Eurico, el primer monarca visigodo, y su hijo Alarico se da un paso más al ocupar éstos el lugar que antes había desempeñado el emperador, ejerciendo sus poderes y facultades. A partir de este momento es cuando podemos hablar propiamente de una legislación visigoda, entre otros, puede verse: Arangio Ruiz, Historia del Derecho romano, 4. $^{\text {a }}$ ed.; trad. esp., (Madrid, 1989), 448 ss. García Moreno, L.A., Historia de la España Visigoda (Madrid, 1989), 317 ss. LaLinde ABADía, El derecho en la historia de la humanidad (Barcelona, 1982), 38 ss. Finalmente hemos de decir que son los visigodos uno de los pueblos germánicos más romanizados de los que se asientan en el antiguo territorio del Imperio Romano occidental. Entre los autores modernos no deja de reconocerse la profunda romanización de los reyes visigodos; sobre el particular, ver entre otros, D’ORs, «El Código de Eurico», en Cuadernos de Instituto Jurídico Español, Estudios Visigóticos, II (Roma-Madrid, 1960), 9.

${ }^{60}$ La Lex Visigothotum, conocida también con los nombres de Liber Iudicum o Liber Iudiciorum, es un libro destinado a la práctica forense y consiste en una recopilación de las leyes promulgadas por los monarcas visigodos que lleva a cabo Recesvinto en el año 654. Las leyes del Liber en la forma recesvindiana que ha llegado hasta nosotros - aunque no
} 
godos, concretamente en el texto legal conocido con el nombre de Lex Visigothotam ${ }^{61}$.

En relación con la citada ley nos vamos a referir a una serie de disposiciones contenidas en la misma relativas a la falsificación de documentos, no sin antes recordar que los godos aceptaron de los romanos, entre otras muchas instituciones, el préstamo con interés, el testamento, los impedimentos matrimoniales de parentesco y, sobre todo, el múltiple empleo de documentos escritos en la vida jurídica ${ }^{62}$. La ley de los visigodos presenta un conjunto de normas sobre la falsedad documental que supone una continuidad del sistema romano. Por otra parte, la regulación de los documentos regios, ya conocida en los textos romanos, es en la citada ley objeto de una regulación especial.

Concretamente, los títulos de la LV 7,5: De falsariis scripturarum y 7,6: De falsariis metallorum, conjetura el romanista D'Ors que pueden haber sucedido a un único título simplemente de falsariis $^{63}$ contenido

todas, pues hay alguna excepción — van precedidas de una de las siguientes inscripciones: Antiqua, Flavius Recaredus Rex, Flavius Sisebutus Rex, Flavius Chindasvintus Rex, Flavius Gloriusus Reccesvindus Rex. De forma que, por un lado, recoge leyes cuyos autores aparecen mencionados; y de otro, leyes que estaban recogidas ya en libros. Las leyes que proceden de recopilaciones llevan la rúbrica antiqua; si los redactores las corrigieron, las colocaron bajo la rúbrica de antiqua enmendata. Un resumen de la historia de la legislación visigótica de Eurico a Witiza puede verse en ZEUMER, Historia de la legislación, tr. esp. por Carlos Clavería (Barcelona, 1944), 64 ss. UREÑa y SMENJAud, La legislación gótico-hispana (Leges Antiquiores-Liber Iudiciorum). Estudio crítico (Madrid, 1905), 45 ss. También IgLesia FerReIRós, La creación del Derecho. Una historia de la formación de un derecho estatal español, (Barcelona, 1992). Puede verse en el citado autor un estudio del proceso de formación de la legislacion visigoda. OsABA, E., El adulterio uxorio en la Lex Visigothorum, (Madrid, 1997), 80-86.

${ }^{61}$ Lex Visigothorum, ed. K. Zeumer en Monumenta Germaniae Historica (Leges), vol. I (Hannover-Leipzig, 1902). En adelante, LV.

62 Cf. Zeumer, Historia de la legislación visigoda, 65.

63 Cf. D’Ors, «El Código de Eurico» en Cuadernos del Instituto Jurídico Español, 12 (Roma-Madrid, 1960), 71. El Código de Eurico fue publicado, según Zeumer, Historia de la legislación, 67, después del año 469, pero antes del 481, alrededor del año 475. En adelante CE. Se han transmitido elementos del CE a través de la Lex Baiuvariorum, por medio de las antiquae contenidas en la Lex Visigothorum, además de los numerosos fragmentos contenidos en el Palimpsesto Parisino (Lat. 12161). Un estudio de conjunto sobre el CE puede verse en D'ORS, «El Código de Eurico». El autor citado establece la fecha del CE en el año 476 d.C. y considera que el Código de Eurico es propiamente un edicto y no un codex como pudo ser el Código Teodosiano, D’Ors, «El Código de Eurico», 3. Según el autor (que ha realizado una edición y palingenesia del texto euriciano) el Código o Edicto de Eurico, aunque posee vestigios o detalles de costumbres germánicas, está profundamente romanizado; en su redacción intervinieron buenos conocedores del Derecho romano - como León de Narbona-; pertenece a la cultura jurídica romana existente en el Sur de las Galias en la segunda mitad del s. v y es, en suma, un monumento de Derecho romano vulgar, ibi- 
en el Código de Eurico. Esta conjetura, sigue diciendo el autor ${ }^{64}$, parece comprobarse por la cita que hace la ley Leovigildiana en LV 2,4,14, antiqua $^{65}$ (en relación con una ley suplantada por Chindasvinto LV 7,5,2) de un título de falsariis, pues resulta claro que no podía haberse hecho una cita así de haber existido más de un título.

En el presente trabajo nos vamos a centrar básicamente en algunas disposiciones de la LV 7,5 que tienen relación, como acabamos de ver, con la falsificación de documentos. Concretamente, la primera ley del título, LV 7,5,166 es una antiqua de Leovigildo que lleva la siguiente rúbrica: De his, qui regias autoritates et preceptiones falsare presumserint. Castiga la citada disposición determinados actos relativos a los documentos regios, reunidos en una serie de apartados: mutare, diluere, substrahere, interponere. Otra serie de actos, en este caso se trata de alteraciones en datos cronológicos del documento, así: tempus aut diem

dem, 1-12. Además de la edición de D’Ors existen las de ZeUMER, K., y una edición más antigua que las citadas anteriormente es la de UREÑA Y SMENJAUD, R., La legislación góticohispana (Leges Antiquiores-Liber Iudiciorum). Pueden verse asimismo las referencias que aparecen en Iglesia Ferreiros, La creación del Derecho, 204-207. Nehlsen, H., Sklavenrecht zwischen Antike und Mittelalter, germanisches und römisches Recht in den Germanischen Rechtsaufzeichnungen. (Götingen, 1972), 153 ss. PetiT, C., Fiadores y fianzas en derecho romano visigodo (Sevilla, 1983), 116, nota 218. Schwerin, «Notas sobre la historia del derecho español más antiguo», en AHDE, 1 (1924), 26 ss. VISMARA, G., «La sucessionne volontaria nelle leggi Barbariche», en Scritti di Storia Giuridica. 6. Le successioni volontarie, 112, nota 13. Posteriormente, el Codex Revisus, conocido también como Código de Leovigildo, publicado probablemente entre los años 572-586 y atribuido al citado monarca, supuso una revisión y una adaptación del Código de Eurico a las nuevas necesidades.

64 Ibídem.

${ }^{65}$ La ley que transcribimos a continuación lleva la rúbrica de antiqua y por lo que respecta a estas leyes sabemos que representan el substrato más antiguo dentro de las leyes que conforman la Lex Visigothorum. LV 2,4,14, antiqua. De his, qui animas suas periurio necant.-Si quis animam suam periurio necaverit, seu quisque pesumtuose periurasse detegitur, aut si quislibet videns se impressum sciendo veritatem negaverit, dum hoc certius iudex agnoverit, addicatur et centum flagella suscipiat et statim sic notam infamie incurrat, tu postea ei testificari non liceat. Et si potentior fuerit, secundum superiorem legem, que De falsariis continentur, insistente iudice quartam partem facultatum suarum amittat, illi consignandam, cui fraudem periurii moliri conatus est.

${ }^{66} \mathrm{LV}$ 7,5,1, antiqua. De his, qui regias autoritates et preceptione falsare presumserint.-Hi, qui in autoritatibus nostris vel preceptionibus aliquid mutaverint, diluerint, subtraxerint aut interposuerint, vel tempus aut diem mutaverint sive designaverint, et qui signum adulterinum sculpserint vel inpresserint: honestior persona mediam partem suarum facultatum amittat, fisci commodis proputuram; minor vero persona manum perdat, per quam tantum crimen admisit. Quod si contingat illos auditores vel iudices mori, ad quos audientia vel iussio destinata fuerat, aut episcopo loci aut alio episcopo vel iudicibus vicinis territorii illius, ubi iussum fuerat negatium terminare, liceat et datam preceptionem oferre et eosdem iudices negotium legaliter hac iustissime ordinare... 
mutare sive designare. Además, otro tipo de actuaciones dolosas tienen relación con sculpere vel imprimere sello falso. Por otra parte, establece la ley leovigildiana citada una serie de sanciones en los términos que vamos a ver en el apartado de las penas. Podemos aquí adelantar que están en función de la clase social y jurídica del autor que ha causado los actos dolosos relativos a los documentos.

En el Fuero Juzgo 7,5, bajo la rúbrica: De los que falsan los escriptos, regula el citado texto legal la falsedad de los documentos, y precisamente la ley de FJ 7,5,167, alude en primer lugar a la falsificación de documentos del rey: una serie de actos dolosos relativos a los mismos que son objeto de la sanción correspondiente.

Si la primera ley del título tiene relación con los documentos regios, como acabamos de decir, la siguiente disposición se refiere a determinados actos relativos a cualquier tipo de escritura. Así, concretamente, una ley del monarca Chindasvinto en LV 7,5,2, bajo la rúbrica: De his, qui scripturas falsas fecerint vel falsare temtaverint, establece una serie de sanciones, también en este caso sanciones diferentes según la condición social y jurídica del autor, cuando éste tenga determinadas conductas dolosas también relativas a los documentos ${ }^{68}$. En primer lugar,

${ }^{67}$ FJ 7,5,1: De los que falsan los escriptos del rey. Cf. la nota 86.

${ }^{68} \mathrm{LV}$ 7,5,2: De his, qui scripturas falsas facerint vel falsare temtaverint.-Si quis scripturam falsam fecerit aut recitaverit vel subposuerit sciens vel in iudicio protulerit, et qui veram subpresserit, subtraxerit, disruperit vel designaverit aut diluerit, quique signum adulterunum sculpserit, fecerit vel inpresserit: talium partem facultatum suarum amittant. Si vero alieno iure debitam scripturam subtraxerint aut vitiaverint, eandem scripturam subtraxisse vel viciasse coram iudice suam professionem depromant; que professio, testibus roborata, perdite vel viciate scripture robor obtineat. Quod si evidentissime, quid scriptura continuit, recordare non potuerit, tunc ille, cuius scriptura fuit, habeat licentiam conprobare per sacramentum suum adque per testem, quid ipsa scriptura continuit evidenter; et ita datum veredice testimonium scripture reparet veritatem. Si vero minor extiterit facultas eorum, quam quod aliis facere conati sunt damnum, ipsi procul dubio cum his, que gabere videntur, eius sevituti subiciantur, eui fraudem fecisse dinoscuntur. De quarta vero parte, quam dari precipimus, principe hordinante vel iudice tres portiones ille accipiat, qui damnum pertulit vel pati potuerat; quarta vero regie potestati servertur, ut, quid exinde fieri debeat, in arbitrio eius consistat. Humiliores sane vilioresque persone, que talia detecti fuerint conmisisse, et iuxta superiorem hordinem conscribere debebunt profesionem, et perpetuo cui fraudem fecerint addicantur ad servitutem; insuper autem tam humiles quam potentes persone centenis flagellorum erunt verberibus coercende. Quod si servi hoc fecerint, et eos alieni iuris esse patuerit, illis consignentur perenniter servituri, quibus scripturam subtraxisse aut celasse vel lesisse fuerint adprobati. Quod si iubentibus dominis suis talia fecerint, omne damnum redundet ad dominum. Ita etiam et de eis precipimus observari, qui lucro suo studentes aliena testamenta vel alias scripturas subpresserint aut vitiaverint, ut his, quibus conpetit, inpedire aliquid possint. Et hii similiter tamquam falsarii teneantur et iuxta qualitatem persone superiori damno multentur. 
distingue la ley: facere, recitare, supprimere, proferre in iudicio scripturam falsam; o actuaciones como, supprimere, substrahere, disrumpe$r$, designare, diluere scripturam veram, o sculpere, facere, imprimere signum adulterinum.

La misma ley contempla el supuesto de falsificación o alteración de documentos ajenos en su propio beneficio, esto es, supprimere, vitiare aliena testamenta vel alias scripturas.

Además, la citada ley de Chindasvinto a la que nos estamos refinendo tiene un añadido por parte de Ervigio $^{69}$, de manera que una disposición del monarca citado insertó en la ley el supuesto de que el propio interesado perdiera el documento por negligencia o descuido ${ }^{70}$.

${ }^{69}$ Podemos referirnos en este lugar a la labor de Ervigio y monarcas posteriores relativa al Liber Iudiciorum. Pocos años después de la aparición del código de Recesvinto se sintió ya la necesidad de acometer una nueva reforma. La revisión del Liber se lleva a cabo en la época de Ervigio (680-687) y lo promulga el monarca citado el año 681. El sucesor de Ervigio, Égica, intentó realizar una nueva redacción pero no se tiene constancia de que la misma llegara a materializarse, aunque se añadieron leyes suyas a los ejemplares oficiales de la LV. A partir de finales del s. VII juristas anónimos añaden a la LV las leyes de Recesvinto que no fueron tenidas en cuenta en la edición recesvindiana de la citada Lex, además de modificaciones y añadidos en los textos legales. Todas estas transformaciones sufridas por la edición ervigiana dan lugar a lo que se conoce con el nombre de redacción Vulgata de la LV y han sido objeto de estudio por GARCía LóPEZ, Y., Estudios críticos y literarios de la Lex Visigothorum (Santiago de Compostela, 1991), 75-475. Finalmente hay que decir que en el s. XIII se traduce la LV al castellano con el nombre de Fuero Juzgo. Afirma ZEUMER que «el código empieza verdaderamente en el Libro II, que lleva la rúbrica De negotiis causarum y que trata preferentemente de la constitución de los tribunales y del proceso. Que sea aquí donde empieza verdaderamente el código es algo que queda señalado externamente con la invocación solemne que precede al primer capítulo, II,I,1: IN NOMINE DOMINI...», Historia de la legislación, 88-89; y más adelante hablando de la redacción ervigiana, establece: «La ley de publicación de Ervigio está al principio del verdadero código que empieza con el libro II. Como II,1,1 y nos informa con frases pomposas y retóricas, sobre el objeto y significación de la labor legislativa», ibídem, 97. Por otra parte, DíAZ y DíAZ, M. "La Lex Visigothorum y sus manuscritos. Un ensayo de reinterpretación», en $A H D E$, 46 (1976), 163-223, excluye este libro primero de la redacción originaria del Liber considerándolo una adición posterior.

70 Disposición de Ervigio en la LV 7,5,2: Quad si de supra taxatis capitulis nihil videatur accidere, id est, qui scripturam alterius repperiatur viciasse, disrupisse, falsasse, celasse, vel si quid in hac lege constitutum est admisisse, sed sola neglegentia, casu adque incuria suam quisque perdiderit acripturam, vel sibi dixerit fuisse ablatam: si testis, qui in eadem scriptura suscripsit, adhuc supprestis existit, per ipsum poterit coram iudice omnis ordo scripture perdite reparari. Quod si testem ipsum, qui in eadem scriptura suscriptor accessit, mortuum esse contigerit, tunc si legitimi et cognitores repperti fuerint alii testes, qui eandem scripturam suscriptor accesit, mortuum esse contigerit, tunc si legitimi et cognitiores repperti fuerint alii testes, qui eandem scripturam se dicant vidisse et omnem texrum vel firmitatem eiusdem scripture plenissime nosse, similiter publica iudicum investigatione per eorum testimonium ille, qui scripturam perdidit, poterit suam reparare et percipere veritatem. 
En la ley de FJ 7,5,2: De los que fazen falsos escriptos ${ }^{71}$ se refiere a las mismas conductas que pueden tener relación con los documentos en los mismos términos que hemos visto en la Ley de los visigodos.

En cuanto a las dos disposiciones de la LV citadas, esto es: LV 7,5,1 y 2 hay que decir que siguen la pauta de la Lex Cornelia testamentaria, según aparece en las PS 5,25, siendo sustituida la pena de deportación por una multa (agravada en caso de falsificación de documentos regios) y otras variantes. Es posible que el mismo modelo hubiera inspirado anteriormente una ley euriciana ${ }^{72}$.

De nuevo encontramos referencias de los documentos regios en la LV 7,5,3, antiqua.-De his, qui sub nomine regis aut iudicis commonitoria falsa sive finxerint sive detulerint ${ }^{73}$. Se trata de una disposición, seguramente leovigildiana, que excluye del falsum a quien simplemente presenta un documento regio de esa índole; pero él está obligado a declarar quién se lo proporcionó; de otro modo, incurre en el crimen. De manera que si los dos son conocedores de la falsedad del documento, son condenados como falsarios. En parecidos términos la disposición

71 FJ 7,5,2 . De los que fazen falsos escriptos.-Si algun omne faze falso escripto, ó lo usar en iudizio, ó otra cosa, sabiéndolo, hy el que desfaze la verda del scripto. Ó que lo rompe; ó quien faze siello, ó seunal falsa, ó que la usa; estos que fazen talas cosas, é los que los conseian, pues que fuern provados, si fueren omnes de grand guisa, pierdan la quarta parte de su buena. E si algun omne furta scripto ajeno. ó lo corrompe, é pues lo manifesta antel iuez é ante testimonias que furtó aquel escripto, ó que lo desfezoó que lo corrompió; el manifiesto que fizo ante las testimonias vala tanto cuemo el escripto valia, que él perdió, ó que corrompió. E si non se pudier acodar de lo que dezia el escripto, estonze aquel, cuyo era el escripto, debe provar por su sacramiento, ó por una testimonia, lo que era contenudo en la carta; é aquela muestra vala tanto cuemo el escripto. E si non oviere tanto en su buena, aquel que furtó el escripto, ó que lo corrompió, quanto fizodanno á aquel cuyo era el escripto, aquel que lo furtó, ó que lo corrompió el escripto, sea siervo con toda su buena daquel cuyo era el escriptto, é de la quarta parte de su buena, que mandamos de suso que debe perder el que furtó el escripto, debe aver las tres partes aquel cayo era el escirpto, y el otra quarta parte debe aver el rey, é faga dello lo que quisiere. E si fuere omne de vil guisa el que furtó el escripto, ó el que lo corrompió, despues que lo manifestare antel iuez, debe se siervo daquel cuyo era el escripto. Hy el omne de grand guisa, ó de vil guisa, si lo fiziere, cada uno dellosdeve recibir C. azotes. E si fuere siervo aieno el que furta el escripto, ó el que locorrompe, ó que lo ascnde sea siervo daquel cuyo era el escripto; é si lo fiziere por mandado de su sennor, el sennor peche todo el danno por él.

72 Cf. D’Ors, «El Código de Eurico», 71.

73 LV 7,5,3, antiqua. De his, qui sub nomine regis aut iudicis commonitoria falsa sive finxerint sive detulerint.- Qui falsa comminatoria sub nomine regis aut iudicis nesciens protulerit, non incurrat falsitatis invidiam, sed eum, qui commonitorium dederit, non moretur ostendere. Quod si eum noluerit nominare, aut quod ab eo commonitorium acceperit, noluerit adprobare, pro qualitate persone ipse reatum falsitatis incurrat, sicut superius continetur de his, qui falsas scripturas confecerint. Quod si ambo falsitatis conscii habeantur, ambo falsarii teneantur. 
contenida en FJ 7,5,374, bajo la rúbrica: De los que falso mandado llevan ó falsan letras de su nombre del rey, ó de iuez.

Asimismo, la última disposición del título, esto es, la LV 7,5, 975, que lleva la rúbrica: De his, qui cifra notarios publicos iussiones ac leges principium recitare vel scribere ausi fuerint, tiene relación con los documentos de los príncipes (que se escriben, se alegan o que los hacen escribir a los notarios). Se advierte en esta ley la existencia de notarios en general, que servían a los falsificadores de mandatos regios, y de notarios del rey o de la corte, a quienes el principal había facultado para realizar las funciones de recitar y tomar por escrito dichos mandatos. No hay referencia a oficiales con la atribución específica de garantizar la autenticidad de los documentos. Hay escritura en el derecho visigótico, pero falta la figura decisiva del notario. Falta el concepto preciso de una fe pública vinculada al oficio ${ }^{76}$.

${ }^{74}$ FJ 7,5,3: De los que falso mandado llevan ó falsan letras de su nombre del rey, ó de iuez.-Quien muestra falso escripto, ó de falso mandado del rey, no lo sabiendo, non debe seer tenudo por falsario, é si pudiere provar aquel que ie lo dio, aquel debe recibir la pena que es de suso dicha, que deven aver los que fazen falsos escriptos. E si ambos lo supieren, ámbos sean penados cuemo falsarios.

75 La disposición citada falta en las ediciones oficiales de Recesvinto y Ervigio de la LV y aparece en la Vulgata como novela, sin que conste nada sobre su autor. Habla la ley citada de los notarios públicos (en ninguna otra ley se habla de tales notarios) y el contenido de LV 7,5,9, Nov., es el siguiente: De his, qui citra notarios publicos iussiones ac leges principium recitare vel scribere ausi fuerint.-Quorundam inlicita actionun perversitas exigit legem ponere pro futuris, ut eos, quos verbi disciplina non corrigit, saltim legalis censura coercendos emendet. Et quia plerosque cognovimus iussiones regias non solum scribere, sed etiam recitare atque scriptas exhibere notariis roborandas, unde diversa in ipsis preceptionibus regni nostri introducentes, vel dictantes atque scribentescapitalia etiam ipsa addi conantur, que nec a nostra celsitudine ordinationis moderamine disponuntur, nec populo Dei congrua cernuntur, nec institutio recte veritatis precipienda decernit, unde et gravissimis damnis atque spoliis vel fatigiis populos ditioni nostre subiectos prospeximus molestari, obinde huius novelle sanctionis edicto censemus: ut modo et deinceps nullus ex notariis querumlibet seu cuiuslibet gentis et generis homo extra notarios publicos vel propios regie celsitudinis eorumque pueros atque illos, quos principalis instituerit preceptionis alloquium, iussiones sive diversas institutiones, que ex nomine regio prescribuntur, recitare, audeat, nullus scribere presumat, nullus recitatum vel scriptum cuilibet notario ad roborandum dare intendat; sed tantum notarii publici ac proprii nostri aut nobis succedentium regum, vel qui a nostra clementia vel ipsis fuerint ordinati, iussiones vel quascumque regias preceptiones recitare et licenter scribere intendebunt. Quicumque tamen ex his cunctis vetitis extiterit deprehensus, utrum ingenuus an fortasse sit servus, principum vel iudicum instantia ducentis flagellorum verberibus cesus, turpiter decalvatus ac insuper pollice in manu dextra absciso se caruise condoleat pro eo, quod contra huius institutionis edicta non sibi licitas conaverit exercere actiones.

76 Sobre el particular, Cf. GIBERT, r., «Prenotariado visigótico», Cuadernos de historia de España (1980), 43. 
Por otra parte, en el mismo título de la ley recesvindiana, las antiquae LV 7,5, 4 a 7, parecen tener un fondo euriciano y se refieren a distintos supuestos de falsificación en los términos que veremos seguidamente. Así, en primer lugar, en LV 7,5,4, antiqua, bajo la rúbrica: De his, qui testamentum contra viventis volumtatem aperuerint, alude la ley a la falsificación de testamento de persona viva en los términos siguientes: Qui viventis testamnetum aut ordinationis eius quamcumque scripturam contra ipsius falsaverit vel aperuerit volumtatem, ut falsarius iudicetur.

Asimismo, el Fuero Juzgo 7,5,477, bajo la rúbrica: De los que falsan la manda del vivo contra su voluntad, establece el citado texto legal que los autores sean castigados como falsarios.

La ocultación o falsificación de testamento de persona fallecida da lugar a que los autores sean castigados como falsarios y lo trata la ley en LV 7,5,5, antiqua, bajo la rúbrica siguiente: De his, qui volumtatem defuncti celare vel falsare pertemtant ${ }^{78}$.

En la versión Vulgata del texto, el Fuero Juzgo 7,5,579, bajo la rúbrica: De los que encubren la manda del muerto, ó que la falsan, de nuevo sanciona al autor como falsario.

Finalmente, la LV 7,5,6, antiqua, establece: Si quis sibi nomen falsum inponat aut parentes vel genus mutet. Como vemos la disposición antiqua citada, tiene relación con la suposición de nombre o cambio de parentela, en los siguientes términos: Qui sibi nomen falsum inponit aut parentes vel genus mutat aut parentes finxeri, aut aliquam inposturam fecerit, reus falsitatis habeatur.

Asimismo en el Fuero Juzgo 7,5,6, ${ }^{80}$ con la rúbrica: Si algun omne se pone falso nombre ó falso linaie ó falsos parientes, sanciona al autor de la misma forma que la $L V$ citada anteriormente.

${ }_{77}$ Fuero Juzgo, 7,5,4: De los que falsan la manda del vivo contra su voluntad.-Quen falsa la manda del omne vivo, ó fiziere escripto de ordinamiento de sus cosas del vivo, ó manisfestare la manda del vivo contra su voluntad, sea iudgado como falso.

${ }^{78}$ LV 7,5,5, antiqua, el texto completo es el siguiente: Qui defuncti celaverit volumtatem aut in eadem aliquid falsitatis intulerit, lucrum, quod forsitam iudicio testatoris per ipsam scripturam fuerat habiturus, amittat, illis, quibus fraudem facere conatus est, profuturum; et insuper pro falsitate ferat infamium. Nam si parvam aut nullam rem exinde consequi potuisset, ut falsarius condemnetur.

79 FJ 7,5,5, el texto completo es el siguiente: Todo omne que encubre la manda del muerto, ó faz alguna falsedat en ela, toda la ganancia que debe aver daquel escripto, pierdala, e gánenla aquellos á quien fizieran el enganno, é sea desfamado por falsario. E si nenguna cosa non debe ende ganar, ó muy poco, sea penado cuemo falsario.

${ }^{80}$ Fuero Juzgo 7,5,6: Si algun omne se pone falso nombre ó falso linaie ó falsos parientes. Quien se pone falso nombre ó falso linaie, ó falsos parientes, ó alguna apostura falsa, sea penado cuemo falsario. 
En todas ellas se sigue el modelo romano de PS 5,25 $5^{81}$ Con relación a las penas, no parecen vislumbrarse penas diferentes para estos distintos supuestos, y no habría que excluir la posibilidad de que en CE una única ley abarcara todo este conjunto, incluyendo la disposición suplantada por la ley $2^{82}$.

\subsection{Las sanciones en la Lex Visigothorum}

En primer lugar, la LV 7,5,1, antiqua que, como hemos visto, tiene relación con determinados actos dolosos relativos a los documentos reales: castiga la falsificación de los actos o preceptos regios, alteración de su fecha o imposición de un sello falso. Establece la citada disposición distintas penas, según la condición social (honestior persona aut minor persona) del causante de los citados actos. Así, honestior persona, mediam partem suarum facultatum amittat, fisci commodis profuturam; por otra parte, minor vero persona manum perdat, per quam tantum crimen admisit. Esta pena es la misma que el rey de los longobardos Rotario ${ }^{83}$ y Carlomagno establecieron para el falsificador

${ }^{81}$ Cf. el apartado correspondiente a la regulación romana en este mismo trabajo.

82 Cf. D’ORs, «El Código de Eurico», 71. Por otra parte, una cierta equiparación entre el delito de falsum y la venalidad judicial parece deducirse de la disposición contenida en LV 5,7,8, antiqua, donde se aplica la falsarii pena al juez (y al demandante) que producen una sentencia injusta en una causa liberalis. La citada antiqua, bajo la rúbrica: Si ingenuus ad servitium repetatur, vel servus se liberum esse dicat, establece lo siguiente: Si quis ingenuum ad servitium addicere voluerit, ipse doceat, quo ordine ei servus advenerit; et si servus ingenuum se esse dixerit, et ipse simili modo ingenuitatis sue firmam ostendat probationem. Iudex vero eorum recipere testimonium debet, quos meliores adque pluriores esse providerit. Quod si muneris acceptione corruptus iniuste curbaverit innocentem, tam index quam petitor falsarii pena multentur. En la edición ervigiana de la misma ley se estableció: secundum legem aliam de his, qui iniuste iudicaverint, conponere non morentur. Ervigio modificó la redacción de esa ley para hacer la equiparación, no al falsum, sino al juicio venal.

83 Autor del Edictum Rotharii Con el citado cuerpo legal se inicia la actividad legislativa de los longobardos. Para las Leges Langobardorum, ver G. DiLCHER, «Langobardisches Recht», en HRG, 2, 1607-1618, Calasso, F., Medioevo del diritto. 1 Le fonti (Milano, 1954), 106-114. Según Graf, W., Der Ehebruch im fränkischen und deutschen Mittealter unter besondere Berücksichtigung des weltlichen Rechts (Würzburg, 1982), 137, nota 59, se percibe la influencia del derecho justinianeo y visigodo además del alemán e igualmente del derecho consuetudinario antiguo longobardo. La comparación del mencionado Edicto, promulgado el 22 de Noviembre del año 643 y los fragmentos de algunas disposiciones Antiquae transmitidos por el Liber Iudiciorum del monarca Recesvinto, pone de manifiesto la frecuencia con que el legislador lombardo imitó la legislación Leovigildiana, Cf. UREÑA y SMENJAUd, Legislación gotico-hispana (Leges Antiquiores-Liber Iudiciorum). Estudio crítico (Madrid, 1905), 240. 
de escrituras ${ }^{84}$. Es la pena típica aunque no exclusiva del derecho medieval para el escribano prevaricador ${ }^{85}$.

Finalmente hemos de decir que el Fuero Juzgo 7,5, dedica un título a la falsificación de los documentos: Titol de los que falsan los escriptos y concretamente la ley 1 del citado título y libro tiene relación con

${ }^{84}$ Edictum Rotharii 247, ed. ZeUMER en MGH, Leges, IV, 1, establece lo siguiente: $S i$ quis cartam falsam scripserit, aut quodlibet membranum, manuseius incidatur; Capitula Karoli Magni, en MGH, cap. 1; 803-813: 2, Si inventus fuerit quis cartam falsam fecisse aut falsum testimonium dixisse, manum perdat aut redimat.

${ }^{85}$ Cf. Las Partidas 3,19,16, que bajo la rúbrica: Que pena deuen auer los escribanos de casa del Rey, é los de las ciudades que fizieren falsedad en su officio, se manifiesta de la siguiente manera: Falsedad faziendo escriuano de la corte del Rey en carta, o en preuilegio deue morir por ello. E si por auentura a sabiendas descubriere poridad que el Rey le ouiesse mandado guardar a ome de quien le viniesse estorno, o daño, deuele dar pena qual entendiere que merece: si el escriuano de ciudad o de villa ficiere alguna carta falsa, o fiziere alguna falsedad en juyzio en los pleytos que le mandaren escreuir, deuenle cortar la mano con que la fizo e darle por malo por manera que non pueda ser testigo, ni auer ninguna honra mientra biuare. De nuevo, el mencionado texto legal de las Partidas 7, en el Título 7 se va a referir a las falsedades y concretamente en la ley 6, bajo la rúbrica: Que pena merescen los que fazen alguna de las falsedades sobredichas, alude, en primer lugar, a las sanciones que se han de imponer a: cualquier que falsa carta, o priuilegio, o bula, o moneda, o sello de papa, o de rey, o lo fiziere falsar a otri, deue morir por ello. Seguidamente se refiere asimismo a la sanción que se le puede imponer a un escribano, en los siguientes términos: E si escribano de algun concejo fiziere carta falsa, cortenle la mano con que la escriuio, e finque enfamado para siempre.

Bajo este nombre de las Siete Partidas se conoce la obra legal más importante de Alfonso X y seguramente de toda la historia jurídica española, vid. PÉREZ MARTín, «La obra legislativa alfonsina y puesto que en ella ocupan las Siete Partidas», Glossae. Revista de historia del derecho europeo, 3 (1992), 30 ss. Las otras obras que se le atribuyen a Alfonso X el Sabio son el Fuero Real y el Espéculo. Por lo que respecta a las Siete Partidas, constituyen un cuerpo jurídico de mayor alcance que la otras dos obras citadas por su planteamiento más doctrinal y su entidad más bien enciclopédica y puede considerarse el libro jurídico más representativo de la recepción del derecho común en Castilla vid., entre otros, Clavero, B., Temas de historia del Derecho: Derecho de los Reinos (Sevilla, 1990), 98. Hay que decir con el autor que las siete partes de que consta la obra abarcan prácticamente todo el sistema de derecho de la época, aunque con frecuencia de forma bastante genérica, sin descender en todos los casos a la regulación concreta de las instituciones jurídicas que contempla.

Según García y García, el rey Fernando III el Santo y Alfonso X el Sabio usaron la ley visigoda para unificar legislativamente el Reino de Castilla, lo cual preludia y acompaña la recepción del derecho común que se verifica en gran escala en Castilla, cuya colección de las Siete Partidas parece inspirarse en el modelo del Digesto, y el Fuero Real representaría el papel del Código justinianeo, «El derecho común en Castilla durante el siglo XIII». Glossae. Revista de Historia del Derecho Europeo 5-6. (Murcia, 1993-94), 55. Las Siete Partidas, en Códigos Antiguos de España, ed. M. Martínez Alcubilla (Madrid, 1885). 
la falsificación de los escritos del rey ${ }^{86}$. Impone la citada ley diferentes sanciones, según quien sea el autor: de forma que: si es omne de grand guisa, peche al rey la meatad de toda su buena; é si fuere omne vil pierda la mano con que fizo aquel pecado.

Con relación a la falsificación de documentos privados, la ley de Chindasvinto en LV 7,5,2, establece también distinta regulación, en función de la clase social y jurídica de los autores de la falsificación de los documentos (según se trate de potentiores, humiliores vel servi). Las sanciones se establecen en los siguientes términos: si potentiores sunt, quartam partem facultatum suarum amittant; no siendo suficiente aquella cuarta parte de los bienes, de la cual una cuarta porción iba a parar al príncipe, para reparar el daño causado, en este caso el culpable caía en esclavitud en favor del perjudicado. Con respecto a la pena de los humiliores, establece la ley lo siguiente: humiliores sane vilioresque persone, que talia detecti fuerint conmisisse, ex iuxta superiorem hordinem conscribere debebunt professionem, et perpetuo cui fraudem fecerint addicantur ad servitutem. Además, unos y otros eran castigados con cien azotes. Con relación a los siervos causantes de la falsificación de documentos, la citada ley de Chindasvinto prevé dos supuestos diferentes, esto es, si el siervo que falsifica el documento pertenece a dueño distinto de aquel a quien le falsifican y establece lo siguiente: Quod si servi hoc fecerint, et eso alieni iuris esse patuerit, illis consignentur perenniter servituri, quibus scripturam subtraxisse aut celasse vel lesisse fuerint adprobati. El siguiente supuesto, si lo hizo por mandato de su dueño: Quod si iubentibus dominis suis talia fecerint, omne damnum redundet ad dominum.

En parecidos términos, el Fuero Juzgo, 7,5,287, con la rúbrica: De los que fazen falsos escriptos, establece el texto legal citado una serie de distinciones que están también en función de la condición social y jurídica del causante de la falsificación: Si fueren omnes de gran guisa, pierdan la cuarta parte de sus bienes. Por otra parte: E si fuere omne de vil guisa, el que furtó el escripto, ó el que lo corrompió, despues que lo manifestare antel iuez, debe ser siervo daquel cuyo era el escripto. Además, establece en ambos casos: Hy el omne de grand guisa,

${ }^{86}$ Fuero Juzgo 7,5,1, De los que falsan los escriptos del rey.-Quien mudar alguna cosa de mandado del rey, ó desficiare. Ó ennadiere, ó en tiempo, ó en dia, ó en otras cosas; hy el que falsar el siello del rey ó otra sennales, si es omne de grand guisa, peche al rey la meatad de toda su buena; é si fuere omne vil, pierda la mano con que fizo aquel pecado; é si por ventura viniere, que aquellos iuezes murieren á quien es enviado aquel mandado del rey, el obispo del logar, ó otro obispo deven dar aquel mandado á los otros iuzes vezinos de la tierra, que lo iudguen, é acaben el pleyto cuemo los otros.

87 Fuero Juzgo 7,5,2, cf. la nota 71. 
o de vil guisa, si lo fiziere, cada uno dellos deva recibir C. azotes. E si fuere siervo aieno el que furte el escripto, quel que lo corrompe, ó que lo asconde, sea siervo daquel cuyo era el scripto; é si lo fiziere por mandado de su sennor, el sennor peche todo el danno por él.

En todo caso, este régimen general es compatible con el tratamiento específico de ciertos casos, tales como el que recoge la disposición antiqua de LV 7,5,988, De his, qui cifra notarios publicos iussiones ac leges principum recitare vel scribere ausi fuerint. Desde el punto de vista de las sanciones se establece en la disposición citada una unificación de penas tanto respecto del siervo como del hombre libre, a quienes trata en una disposición que falta en las ediciones oficiales de Recesvinto y Ervigio de la Ley de los visigodos y que aparece en la Vulgata como novela, sin que nada conste sobre su autor y además hay que destacar que hace una mención expresa a los notarios públicos ${ }^{89}$. Las sanciones según la ley citada consisten en la amputación del pulgar derecho, además de doscientos azotes y marcas infamantes. Estas mismas penas se establecen en el FJ 7,5,9: De los que escriben las leyes del rey falsamientre, o las que dan á otri que las escriban ${ }^{90}$.

${ }^{88} \mathrm{LV}$ 7,5,9. De his, qui cifra notarios publicos iussiones ac leges principium recitare vel scribere ausi fuerint, cf. la nota 75.

${ }^{89}$ Con relación a las scripturae y scribae en el reino visigodo, vid, Bono, José, Historia del derecho notarial español, T. I, 1 (Madrid, 1979), 81 ss.; T. I, 2 (Madrid, 1982). Se puede decir con el autor citado que todo el sistema del derecho privado visigodo está dominado por la idea de la escrituriedad, y cada negocio jurídico puede ser conformado a través de una scriptura. La actividad de estos scribae (notarios públicos, dice la LV 7.5,9), debió versar no sólo sobre la escrituración de actos y contratos de particulares, sino abarcar también la redacción de los actos judiciales (iudicia) y de las actuaciones que tenían lugar ante el obispo en materia testamentaria y en las manumisiones, Idem, 82 .Otro testimonio de la actividad de los scribae es el de San Isidoro (Etymol. 9,4,27) que al tratar del ordo curiae incluye al scriba publicus ( = tabellio, exceptor) como el que escribe los documentos que se protocolizan en la curia minicipal. Este cometido era el que desempeñaron los tabularii de la época romana.

${ }^{90}$ La versión en el Fuero Juzgo 7,5,9, es la siguiente: De los que escriben las leyes del rey falsamientre, ó las que dan á ótri que las escriban.-Los males de algunos omnes nos facen poner ley pora los que son de venir, é que aquellos que non se quieren castigar por palabra, si al que no, que se castiguen por la pena de la ley. E por que vimos ya algunos que escribian leyes de rey falsamientre, é que las alegaban falsamientre, ó que las fazian escriver á los notarios por las confirmar, onde metien muchas cosas en nuestras leyes, hy escribien que non eran ordenadas, nin pora nos, nin eran convenibles á nuestro pueblo, nin provechosas, é que fazien grande danno á nuestros pueblos: por ende defendemos en esta nueva ley que ningun omne daqui adelantre, si non fuere escrivano comunal de pueblo, ó del rey, ó tal omne, á quien mande el rey, que non ose allegar falsas constituciones, nin falsos scriptos del rey, nin escribir, nin dar á ningun escrivano que escriba falsamientre. Mas los escrivanos del pueblo, ó los nuestros, ó a quien nos mandaremos, las escrivan, é las lean las nuestras constituciones, é non otrí. E si algun omne fuere contra este defendimiento, si quier sea libre ó siervo, el iuez. le faga dar CC. azotes, é sea sennalado laydamientre; é fagale demas cortar el polgar de la mano diestra, por que vino contra nuestro mandado, é contra nuestro defendimiento. 
Otro ejemplo de tratamiento específico, lo tenemos en la disposición contenida en LV 7,5,5, antiqua, sobre falsificación del testamento de quien ha fallecido, añadiendo la citada ley a la pena ordinaria la de infamia: et insuper pro falsitate ferat infamium, y la obligación de devolver los beneficios que el autor del delito hubiera percibido ilegítimamente. Finalmente en LV 7,5,891, una disposición de Chindasvinto sanciona la falsa escritura de donación con las penas patrimoniales y físicas ya en vigor, a las que añadió la obligación que le incumbe al autor de la falsedad de cumplir la promesa posterioribus scripturis confectis ${ }^{92}$.

91 El texto de la disposición del monarca Chindasvinto en LV 7,5,8, establece, bajo la rúbrica: De callide et fraudulenter posterioribus scripturis confectis.- Non inmerito cogitur debitum heredis exolvere, qui succesor hereditatis noscitur extitisse. Quia ergo nullis fraudem necesse est occasionibus excusare huius perpetim valiture legis sanctione censemus, ut, quicumque cuilibet per cuiuscumque scripture contractum res quascumque dederit, que tamen repperiantur quandoquidem aut non eius iuris fuisse, qui dedit, aut id, quod dedisse videtur, per priorem scripturam aut quamcumque definitionem in cuiuscumque prius nomine obligasse et sub quodam argumento id postmodum alteri dedisse, quod aut suum non erat, aut iam prius alteri dederat, dum fraudis huius conmentum manifeste patuerit, ipse quidem, qui fecit, si suprestis est, et promissionem et penam, quam ab eo edita scriptura testatur, subplere cogendus est...

92 También el Fuero Juzgo 7,5,7, establece lo siguiente: De los escritos que son fechos, que dizen que eran fechos despues, é eran fechos ante.-Non es tuerto que aquel que a la buena del muerto, que pague la debda. E porque el omne que faze el enganno non debe aver nenguna escusacion: por ende establecemos por esta ley que todo omne que da á otrí alguna cosa por escripto, é aqueta cosa nunqua fue en so poder, ó tal cosa que avie ante empennada á otrí, é por algun enganno diola é éste lo que empennara ante á otri, ó lo que non era so, pues que esto pudiera ser provado, si aquel que fizo este enganno es vivo debe pagar la pena, é quanto prometiera en el scripto. E si despues de su muerte pudiere seer provado el enganno, sos erederos lo deven todo pagar. E si aquello que prometió es mas que toda su buena, los que tienen lo buena dexen la buena por emienda, si non quisieren pagar aquello: hy esto mismo mandamos guardar, que si aquel á quien fuera la cosa empennada primeramientre sopiera el enganno, el qui lo fizo el enganno, y el que lo sopo, paguen egualmientre la pena, é quanto fuera prometido, é reciban en sus cuerpos, hy en sus casas el danno que dize la ley de suso de los falsos. 